\title{
Disruptive Effect of Chloroquine on Lysosomes in Cultured Rat Hepatocytes
}

\author{
Akihiro Michinara, Ken Toda, Takuo Kubo, Yoshiteru Fusiwara, Kenji Akasaki, ${ }^{*}$ and Hiroshi TsujI \\ Faculty of Pharmacy and Pharmaceutical Sciences, Fukuyama University; Fukuyama, Hiroshima 729-0292, Japan. \\ Received December 9, 2004; accepted March 17, 2005
}

\begin{abstract}
Chloroquine has been used as an anti-malarial drug and is known as a lysosomotropic amine as well. The effects of chloroquine on lysosomal integrity in cultured rat hepatocytes were studied by measuring lysosomal enzyme $\beta$-glucuronidase ( $\beta$-G) or lysosomal membrane glycoprotein (lamp-1) in Percoll density gradient fractions, in the cytosolic fraction obtained from cells permeabilized by digitonin or in the cytosolic fraction obtained by conventional cell fractionation. The distribution of $\beta-G$ on a Percoll density gradient in chloroquine-treated cells was approximately similar to that of a cytosolic protein, mevalonate pyrophosphate decarboxylase, in nontreated cells. Lamp-1 was decreased in the lysosomal fractions on a Percoll density gradient in chloroquine-treated cells, and was increased in the plasma membrane fraction, as compared with the levels in nontreated cells. Furthermore, after cells were cultured in the presence and absence of chloroquine, the proportions of $\beta$-G activity in the cytosolic fraction obtained from the digitonin-permeabilized cells were $19 \%$ and $4 \%$, while those in the cytosolic fraction obtained by conventional cell fractionation were $54 \%$ and $26 \%$, respectively. From these findings, we infer that chloroquine caused the disruption of lysosomes in the living cells, and that lysosomes treated with chloroquine were easily disrupted by homogenization or centrifugation during cell fractionation.
\end{abstract}

Key words chloroquine; lysosome; cytosol; lamp-1; $\beta$-glucuronidase

Lysosomes are membrane-bound organelles whose matrixes contain many hydrolytic enzymes that are optimally active at an acidic $\mathrm{pH}^{1-3)}$ The intralysosomal environment is maintained at $\mathrm{pH} 4.5$ by membrane-integrated $\mathrm{H}^{+}$-ATPase. ${ }^{4)}$ Lysosomes receive extracellular macromolecules through the endocytic transport system. Intracellular proteins are sequestered into lysosomes via autophagocytosis. A variety of lysosomotropic amines have been employed to analyze the lysosomal biogenesis and function. ${ }^{5-7)}$ There is general agreement that these amines inhibit protein degradation in lysosomes and dissociation of receptor-ligand complexes in endosomes. Biosynthetic transport of newly synthesized lysosomal enzymes is affected by these amines, causing their secretion into the extracellular space.

Chloroquine has been used as an anti-malarial drug and is known as a lysosomotropic amine as well. Previous reports demonstrated that chloroquine is accumulated in lysosomes and consequently often causes a shift of lysosomes to a less dense fraction upon isopycnic centrifugation of a mitochondrial fraction (into a fraction containing lysosomes but not the cytosolic fraction) in a sucrose gradient. ${ }^{8,9)}$ However, it is not known whether the chloroquine-induced shift of lysosomes to the less dense fraction is caused by a change of lysosomal buoyant density or by the disruption of lysosomes.

In the present study, the effects of chloroquine on lysosomal integrity in cultured rat hepatocytes were studied by measuring $\beta-\mathrm{G}$ or lamp-1 in Percoll density gradient fractions, in the cytosolic fraction obtained from cells permeabilized by digitonin or in the cytosolic fraction obtained by conventional cell fractionation.

\section{MATERIALS AND METHODS}

Materials Male Wistar rats weighing $200 \mathrm{~g}$ were obtained from Shimazu Experimental Animals (Kyoto, Japan). Percoll and the ECL Western blotting detection kit were from Amersham Pharmacia Biotech (Tokyo, Japan). Chloroquine was purchased from Sigma-Aldrich Japan Co. (Tokyo, Japan). Specific anti-rat lamp-1 IgG was prepared in a previous study. Antiserum against rat MPD was prepared in a previous study. Horseradish peroxidase (HRP)-conjugated antirabbit IgG goat IgG was bought from O.E.M. Concepts, INC. (Toms River, NJ, U.S.A.). Eagle's essential medium and Hank's solution were obtained from Nissui Co. (Tokyo, Japan). Complete Mini (tablet containing protease inhibitor) was purchased from Roche. All other chemicals were of reagent grade, and were purchased from various commercial sources.

Cultured Rat Hepatocytes Rat hepatocytes were prepared from rat livers by collagenase perfusion as described by Seglen. ${ }^{10)}$ Hepatocytes were diluted to $3 \times 10^{6}$ per $60-\mathrm{mm}$ tissue culture dish with Eagle's essential medium containing $10 \%$ fetal calf serum, then incubated in humidified air containing $5 \% \mathrm{CO}_{2}$ at $37^{\circ} \mathrm{C}$ for $24 \mathrm{~h}$.

Cell Fractionation by Percoll Density Centrifugation Cells incubated in $60 \mathrm{~mm}$ tissue culture dishes were washed several times in cold Hank's buffer, then in a cold isotonic sucrose solution $(0.25 \mathrm{~m}$ sucrose, $1 \mathrm{~mm}$ EDTA, $1 \mu \mathrm{m}$ pepstatin A, $1 \mu \mathrm{M}$ leupeptin, $1 \mu \mathrm{M}$ PMSF, complete Mini, $10 \mathrm{~mm}$ Tris-HCl buffer, $\mathrm{pH}$ 7.3), and removed from the dish using a rubber policeman. About $3 \times 10^{6}$ cells in $1.5 \mathrm{ml}$ of the sucrose solution were homogenized with 5 strokes in a Teflon homogenizer, then centrifuged at $650 \times \boldsymbol{g}$ for $5 \mathrm{~min}$. The postnuclear supernatant (PNS; $1.0 \mathrm{mg} / \mathrm{ml}$ ) was diluted with Percoll to a final concentration of $30 \%$ and centrifuged at $25000 \mathrm{rpm}$ for $30 \mathrm{~min}$ in a Beckman 70.1 Ti rotor. Following centrifugation, the gradients were divided into $18 \times 0.5 \mathrm{ml}$ fractions by downward displacement. The densities of the gradient fractions were obtained from the refractive indices.

Cell Permeabilization Cell permeabilization by digitonin was carried out according to the method of Michihara et al. ${ }^{11)}$ Chloroquine-treated or nontreated rat hepatocytes were incubated in $1.5 \mathrm{ml}$ of KHM buffer ( $20 \mathrm{~mm}$ phosphate buffer [pH 7.2], $110 \mathrm{~mm} \mathrm{KOAc,} 2 \mathrm{~mm} \mathrm{MgOAc)}$ in the pres- 
ence of digitonin $(40 \mu \mathrm{g} / \mathrm{ml})$ for $5 \mathrm{~min}$ at $4{ }^{\circ} \mathrm{C}$, and the cells were homogenized with $1.5 \mathrm{ml}$ of cold isotonic sucrose solution containing $1 \%$ Triton $\mathrm{X}-100 . \beta-\mathrm{G}$ activity in the cells (M/O; membrane/organelle fraction) and medium (cytosol fraction) was measured and expressed as a percentage of the total.

Conventional Cell Fractionation Cell fractionation was carried out according to the method of de Duve et al. ${ }^{12)}$ After chloroquine-treated or nontreated rat hepatocytes were homogenized with $1.5 \mathrm{ml}$ of isotonic sucrose solution, the homogenate was centrifuged at $650 \times \boldsymbol{g}$ for $5 \mathrm{~min}$. The PNS was centrifuged at $106000 \times \boldsymbol{g}$ for $1 \mathrm{~h}$. The supernatant was designated as the cytosol fraction. $\beta-\mathrm{G}$ activity in the PNS containing $1 \%$ Triton $\mathrm{X}-100$ and in the cytosol fraction was measured. $\beta-\mathrm{G}$ activity in $\mathrm{M} / \mathrm{O}$ was calculated from $\beta-\mathrm{G}$ activity in the PNS containing 1\% Triton X-100 and in the cytosol fraction, and was expressed as a percentage of the total.

Enzyme Assays $\beta$-G, APDE I (alkaline phosphodiesterase I) and LDH (lactate dehydrogenase) were assayed as described by Robins et al., Ikehara et al. and Abei et al., respectively. ${ }^{13-15)}$

Protein Determination Protein levels were measured by the method of Lowry et al. using bovine serum albumin as the standard. ${ }^{16)}$

Gel Electrophoresis Sodium dodecyl sulfate-polyacrylamide gel electrophoresis (SDS-PAGE) was performed on $12 \%$ slab gels according to Laemmli. ${ }^{17}$

Immunoblot Procedures Proteins in an SDS-slab gel were transferred to a nylon membrane by electrophoresis using a modified version of the procedure of Towbin et al. ${ }^{18)}$ Immunoreactive bands were visualized using an ECL Western blotting detection kit. Densities of the immunopositive bands were quantified with an Intelligent Quantifier (Bio Image).

\section{RESULTS}

Chloroquine-Induced Change of Subcellular Distribution of $\boldsymbol{\beta}$-Glucuronidase in Rat Hepatocytes as Shown by Percoll Density Gradient Centrifugation To establish whether the chloroquine-induced shift of lysosomes to a less dense fraction was caused by a change of lysosomal buoyant density or by the disruption of lysosomes, we first examined the subcellular distribution of marker enzymes in rat hepatocytes by Percoll density gradient centrifugation. As shown in Fig. 1, the major peaks of $\beta$-G (lysosomal marker enzyme) and APDE I (plasma membrane marker enzyme) appeared in fractions 17 and 5, respectively. Mevalonate pyrophosphate decarboxylase (MPD), a cytosolic protein was predominantly located in fractions other than fractions 17 and 18. These findings suggest that lysosomal matrix enzymes released into the cytosol due to the disruption of lysosomes would be detected in fractions other than fractions 17 and 18, if chloroquine caused the disruption of lysosomes. To clarify the effects of chloroquine on the total amount of lysosomal marker enzymes in cells and on lysosomal buoyant density, we examined the specific activity of $\beta$-G between chloroquinetreated and nontreated rat hepatocytes, and the distribution of $\beta-\mathrm{G}$ in Percoll density gradients of homogenates obtained from rat hepatocytes treated with $50 \mu \mathrm{M}$ chloroquine for 180 min. As shown in Table 1 , the specific activity of $\beta$-G in
A

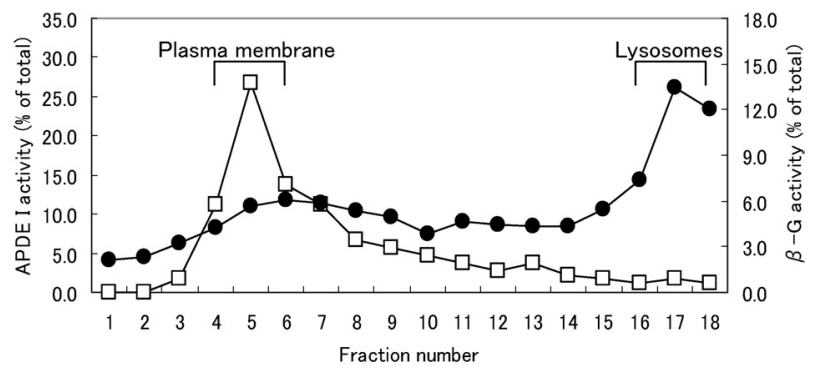

B

Fraction number

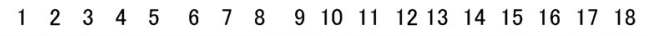
$45 \mathrm{kDa}-$

$\mathrm{C}$

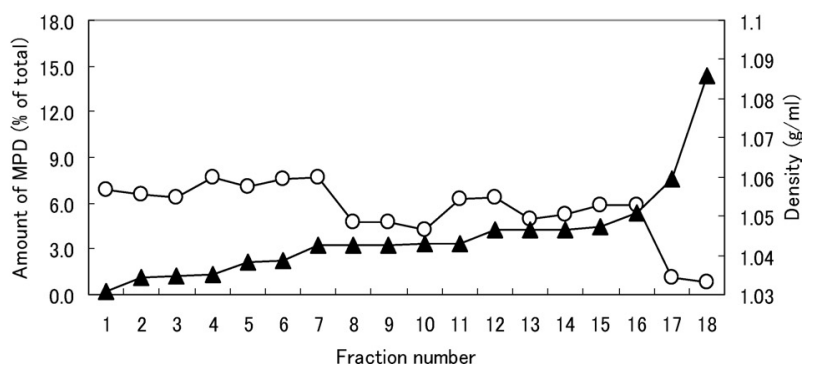

Fig. 1. Distribution of Marker Enzymes in Percoll Density Gradient Fractions from Cultured Rat Hepatocytes

Primary monolayer cultures of rat hepatocytes were homogenized and centrifuged at $650 \times \boldsymbol{g}$ for $5 \mathrm{~min}$. The post-nuclear supernatant (PNS; $1.0 \mathrm{mg} / \mathrm{ml}$ ) was centrifuged on a Percoll gradient. The gradient was divided into 18 fractions in a downward direction. (A) The distributions of $\beta$-Glucuronidase ( $\beta$-G; lysosomal marker enzyme; $\mathbf{0})$ and alkaline phosphodiesterase I (APDE I; plasma membrane marker enzyme; $\square$ ) are shown. (B) Each fraction was subjected to immunoblot analysis using an anti-rat MPD antiserum. (C) Signals of MPD $(O)$ in A and density $(\boldsymbol{\Delta})$ were measured using Intelligent Quantifier and a refractometer, respectively. $\beta-\mathrm{G}$ and APDE I activity and amount of MPD were expressed as a percentage of the total. Data are the means of three identical experiments.

Table 1. Comparison of Specific Activity of $\beta$-Glucuronidase between Chloroquine and Nontreated Rat Hepatocytes

\begin{tabular}{lccc}
\hline \hline & $\begin{array}{c}\text { Activity } \\
(\mathrm{nmol} / \mathrm{min} / \mathrm{ml})\end{array}$ & $\begin{array}{c}\text { Protein } \\
(\mathrm{mg} / \mathrm{ml})\end{array}$ & $\begin{array}{c}\text { Specific activity } \\
(\mathrm{nmol} / \mathrm{min} / \mathrm{mg})\end{array}$ \\
\hline Chloroquine-treated cells & 2.5 & 1.5 & 1.67 \\
Nontreated cells & 2.1 & 1.2 & 1.75 \\
\hline
\end{tabular}

chloroquine-treated cells was similar to that in nontreated cells. In Percoll density gradient fractionation, concomitantly with the disappearance of $\beta-\mathrm{G}$ activity in the lysosomal fractions (fractions 16 to 18), i.e., the highest density fractions, $\beta-\mathrm{G}$ activity was elevated in each fraction other than the lysosomal fractions (Fig. 2). These findings suggest that the amount of $\beta-\mathrm{G}$ in cells was not affected by chloroquine, and that chloroquine caused the disruption of lysosomes, as the distribution of cytosolic protein in the Percoll density gradient of nontreated cells was similar to that of $\beta-G$ in the gradient of chloroquine-treated cells. Next, we examined the timecourse and dose-dependency of the level of $\beta-\mathrm{G}$ activity in the lysosomal fractions. When the level of $\beta$-G activity in the lysosomal fractions in Percoll density gradients of cells cultured in the presence $50 \mu \mathrm{M}$ chloroquine for various periods 


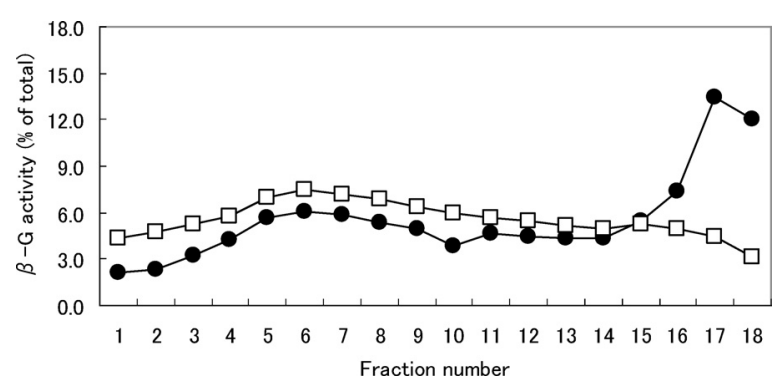

Fig. 2. Effects of Chloroquine on Subcellular Distribution of $\beta$-G

Rat hepatocytes were cultured in the presence $(\square)$ or absence $(\bullet)$ of $50 \mu \mathrm{M}$ chloroquine for $3 \mathrm{~h}$. Thereafter, the cells were homogenized in an isotonic sucrose solution and centrifuged at $650 \times \boldsymbol{g}$ for $5 \mathrm{~min}$. The PNS $(1.0 \mathrm{mg} / \mathrm{ml})$ was centrifuged on a Percoll density gradient, giving eighteen fractions of $0.5 \mathrm{ml}$ each. $\beta$-G activity in each fraction was measured and was expressed as a percentage of the total. Data are the means of three identical experiments.

\section{A}

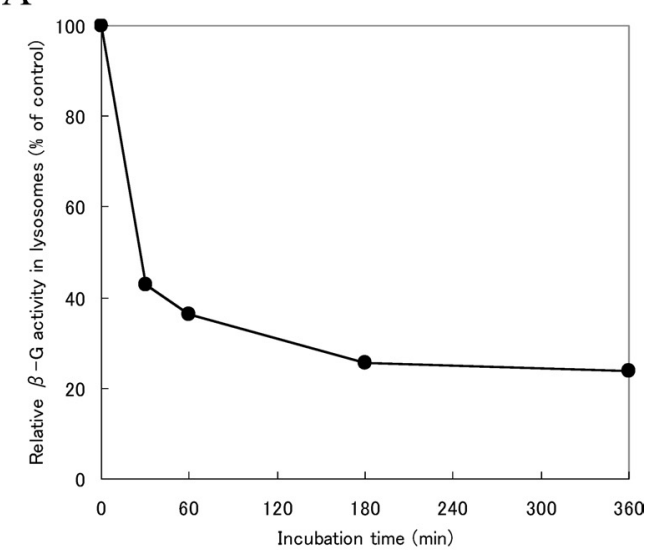

$\mathrm{B}$

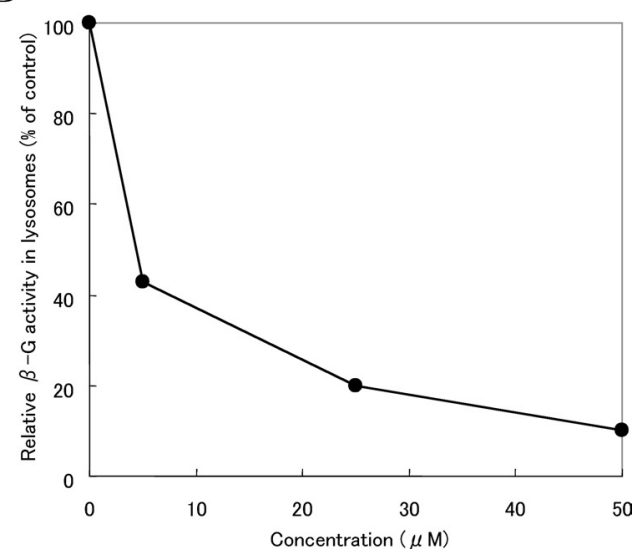

Fig. 3. Time-Course and Dose-Dependency of the Effect of Chloroquine on the Level of $\beta-\mathrm{G}$ in the Dense Lysosomal Fraction

(A) Using Percoll gradient centrifugation, lysosomal fractions (fractions 16-18, see Fig. 1) were prepared from hepatocytes incubated with and without $50 \mu \mathrm{M}$ chloroquine for the indicated periods of time. $\beta$-G activity in the lysosomal fraction was measured. Relative $\beta$-G activity is shown on the vertical axis as the ratio of $\beta$-G activity in lysosomes from chloroquine-treated versus nontreated hepatocytes and is expressed as 100 at time 0. (B) lysosomal fractions were prepared from hepatocytes incubated for $3 \mathrm{~h}$ with various concentration of chloroquine. $\beta$-G activity in the lysosomal fraction was determined. Relative $\beta$-G activity is shown on the vertical axis as the ratio of $\beta$-G activity in lysosomes from chloroquine-treated versus nontreated hepatocytes and is expressed as 100 at time 0 . Data are the means of three identical experiments, and the variation of the values was $5 \%$.

of time was examined, it was found that $\beta$-G activity in the lysosomal fractions was reduced in a time-dependent manner, declining to half of the initial level at $25 \mathrm{~min}$ and to the
A

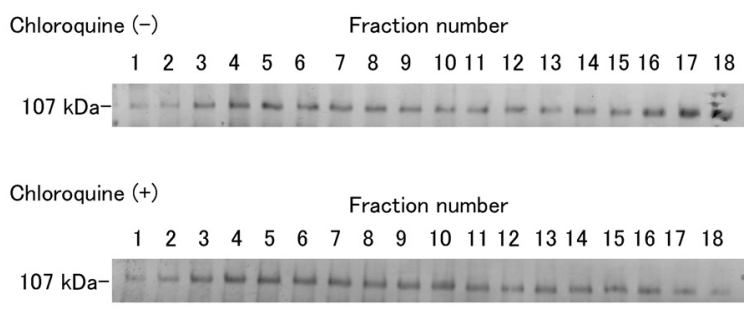

B

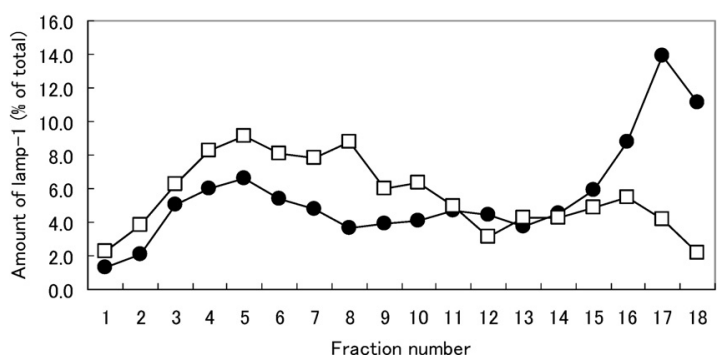

Fig. 4. Effects of Chloroquine on Subcellular Distribution of Lamp-1

Rat hepatocytes were cultured in the presence $(\square)$ or absence $(\bullet)$ of $50 \mu \mathrm{M}$ chloroquine for $3 \mathrm{~h}$. Thereafter, the cells were homogenized in an isotonic sucrose solution and centrifuged at $650 \times \boldsymbol{g}$ for $5 \mathrm{~min}$. The resultant PNS $(1.0 \mathrm{mg} / \mathrm{ml})$ was centrifuged on a Percoll density gradient, giving eighteen fractions of $0.5 \mathrm{ml}$ each. (A) Each fraction $(20 \mu \mathrm{l})$ was subjected to immunoblot analysis using an anti-rat lamp-1 antiserum. (B) Signals in A were measured using Intelligent Quantifier. The amount of lamp-1 was expressed as a percentage of the total. Data are the means of three identical experiments.

baseline level by 180 min (Fig. 3A). Furthermore, when the level of $\beta$-G activity in the lysosomal fractions in Percoll density gradients of cells cultured in the presence of various concentrations of chloroquine for $180 \mathrm{~min}$ was examined, it was found that the $\beta$-G activity in the lysosomal fractions was reduced in a dose-dependent manner, declining to half of the initial level at $4 \mu \mathrm{m}$, and that the concentration of chloroquine causing maximum reduction of $\beta-\mathrm{G}$ activity was $50 \mu \mathrm{M}$ (Fig. 3B). These findings indicate that the chloroquine-treatment conditions causing maximal disruption of lysosomes were $180 \mathrm{~min}$ of treatment with $50 \mu \mathrm{M}$ chloroquine.

Chloroquine-Induced Change of Subcellular Distribution of Lysosomal Glycoprotein in Rat Hepatocytes as Shown by Percoll Density Gradient Centrifugation Since lamp-1 is a major component of the lysosomal membrane, it is regarded as an appropriate marker for lysosomal integrity. Therefore, using immunoblot analysis we examined the distribution of lamp-1 in Percoll density gradients obtained from rat hepatocytes treated with $50 \mu \mathrm{m}$ chloroquine for $180 \mathrm{~min}$ or nontreated rat hepatocytes. Lamp-1 as well as $\beta$-G activity was decreased in lysosomal fractions of chloroquine-treated cells as compared with nontreated cells, and lamp-1 was detected as a broad peak roughly cofractionating with the plasma membrane fraction (fractions 4 to 8 ) (Fig. 4). Next, we measured the amount of lamp-1 in the lysosomal fractions in Percoll density gradients of cells cultured in the presence $50 \mu \mathrm{m}$ chloroquine for various periods of time. The relative amount of lamp-1 in lysosomal fractions decreased time-dependently, with a half-life of $50 \mathrm{~min}$ (Fig. 5). These results revealed that the disruption of lysosomes occurred before or during the process of cell fractionation of cells treated with $50 \mu \mathrm{M}$ chloroquine for $180 \mathrm{~min}$.

Disruption of Lysosomes by Chloroquine The above 
A

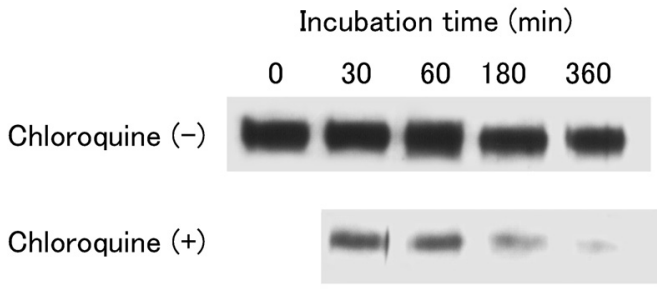

B

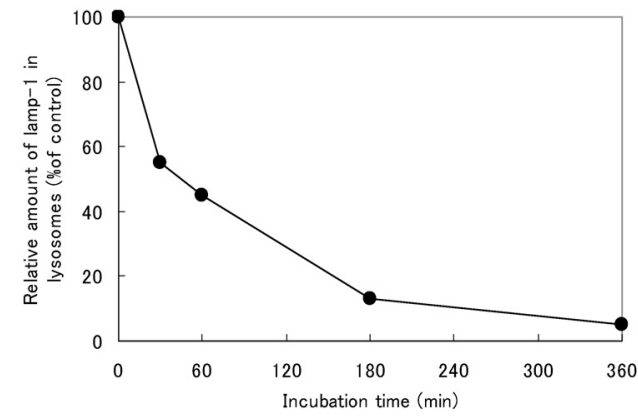

Fig. 5. Chloroquine Induced Reduction of Lamp-1 in the Dense Lysosomal Fraction in a Time-Dependent Manner

(A) Using the Percoll gradient centrifugation, lysosomal fractions were prepared from hepatocytes incubated with $(+)$ and without $(-) 50 \mu \mathrm{M}$ chloroquine for the indicated periods of time. Equal amounts $(40 \mu \mathrm{l})$ of the lysosomal fractions were simultaneously subjected to immunoblot analysis using an anti-lamp-1. (B) Signals of lamp-1 in A were measured using Intelligent Quantifier. The relative amount of lamp-1 shown on the vertical axis is the ratio of arbitrary units of lamp-1 in lysosomes from chloroquinetreated versus nontreated hepatocytes and is expressed as 100 at time 0 . Data are the means of three identical experiments, and the variation of the values was $10 \%$.

experimental results left open the question of whether the disruption of lysosomes by chloroquine occurs initially in the living cells or occurs upon homogenization or centrifugation during cell fractionation. To determine whether the disruption of lysosomes by chloroquine occurs initially in the living cells, we examined the $\beta$-G activity in the cytosolic fraction obtained from the digitonin-permeabilized rat hepatocytes. Digitonin treatment $(40 \mu \mathrm{g} / \mathrm{ml}$ digitonin for $5 \mathrm{~min})$ of rat hepatocytes has been reported to permeabilize the plasma membrane reversibly, leaving subcellular organelles intact. ${ }^{11)}$ Therefore, after cells were incubated in the presence or absence of chloroquine, $\beta-\mathrm{G}$ activity in the permeabilized cells (M/O fraction; membrane/organelle fraction) or medium (cytosolic fraction) was examined under the same conditions described above. As shown in Fig. 6A, the proportions of $\beta$-G activity in the cytosolic fraction and $\mathrm{M} / \mathrm{O}$ fraction from nontreated cells were 4 and $96 \%$, respectively, while those in the fractions from chloroquine-treated cells were 19 and $81 \%$, respectively. These results indicate that $15 \%$ (obtained by subtracting the $\beta$-G activity [4\%] in the cytosolic fraction of nontreated cells from that $[19 \%]$ in the corresponding fraction of chloroquine-treated cells) of the $\beta-\mathrm{G}$ was derived from the disruption of lysosomes in the living cells by chloroquine. Next, in order to estimate the amount of $\beta$-G derived from the disruption of lysosomes by homogenization or centrifugation during cell fractionation, the level of $\beta-\mathrm{G}$ activity in the cytosolic fraction obtained by the conventional method of cell fractionation was measured. As shown in Fig. $6 \mathrm{~B}$, the proportions of $\beta$-G activity in the cytosolic fraction and $\mathrm{M} / \mathrm{O}$ fraction in nontreated cells were 26 and $74 \%$, while those in the fractions from chloroquine-treated cells were 54

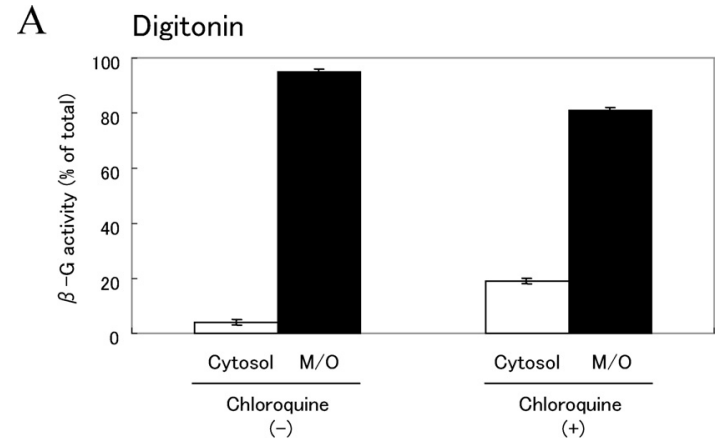

B Cell fractionation

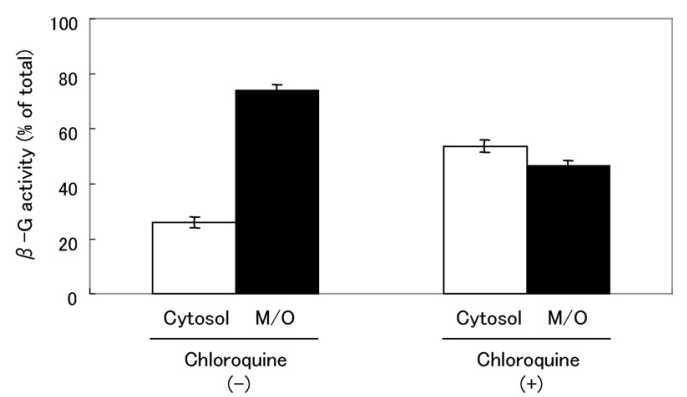

Fig. 6. $\beta-\mathrm{G}$ Activity in the Cytosolic Fraction Obtained from Permeabilized Cells or Conventional Cell Fractionation

(A) Chloroquine-treated or nontreated rat hepatocytes were incubated in $1.5 \mathrm{ml}$ of KHM buffer (20 mM phosphate buffer [pH 7.2], $110 \mathrm{~mm}$ KOAc, $2 \mathrm{~mm} \mathrm{MgOAc}$ ) in the presence of digitonin $(40 \mu \mathrm{g} / \mathrm{ml})$ for $5 \mathrm{~min}$ at $4{ }^{\circ} \mathrm{C}$, and the cells were homogenized with $1.5 \mathrm{ml}$ of isotonic sucrose solution containing $1 \%$ Triton $\mathrm{X}-100 . \beta-\mathrm{G}$ activity in the cells $(\mathrm{M} / \mathrm{O}$; membrane/organelle fraction) and medium (cytosol fraction) was measured and expressed as a percentage of the total. (B) After chloroquine-treated or nontreated rat hepatocytes were homogenized with $1.5 \mathrm{ml}$ of isotonic sucrose solution, the homogenate was centrifuged at $650 \times \boldsymbol{g}$ for $5 \mathrm{~min}$. The PNS was centrifuged at $106000 \times \boldsymbol{g}$ for $1 \mathrm{~h}$. The supernatant was designated as the cytosol fraction. $\beta$-G activity in the PNS containing $1 \%$ Triton $\mathrm{X}-100$ and cytosol fraction was measured. $\beta$-G activity in $\mathrm{M} / \mathrm{O}$ was calculated from $\beta$-G activity in the PNS containing $1 \%$ Triton X-100 and cytosol fraction, and was expressed as a percentage of the total. Data are the means of three identical experiments, and the variation of the values was $5 \%$.

and $46 \%$, respectively. These results indicate that $28 \%$ (obtained by subtracting the $\beta$-G activity [26\%] in the cytosolic fraction of nontreated cells from that [54\%] in the corresponding fraction of chloroquine-treated cells) was derived from the disruption of lysosomes caused before or during the cell fractionation of chloroquine-treated cells. From the results described above for digitonin, $15 \%$ of $\beta$-G was derived from the disruption of lysosomes in the living cells by chloroquine. Therefore, we concluded that $13 \%$ (obtained by subtracting $15 \%$ [derived from the disruption of lysosomes in the living cells by chloroquine] from $28 \%$ [derived from the disruption of lysosomes caused before or during cell fractionation of chloroquine-treated cells]) of $\beta$-G was derived from the disruption of lysosomes by homogenization or centrifugation during cell fractionation of chloroquine-treated cells. Thus, we conclude that chloroquine caused the disruption of lysosomes in the living cells, and that lysosomes treated with chloroquine were easily disrupted by homogenization or centrifugation during cell fractionation

The Survival Rate of Rat Hepatocytes Treated with Chloroquine The above results indicated that $15 \%$ of lysosomes in the living cells were disrupted by chloroquine, and lysosomal enzymes including $\beta$-G were released into the cytosol. To estimate the survival rate of chloroquine-treated 


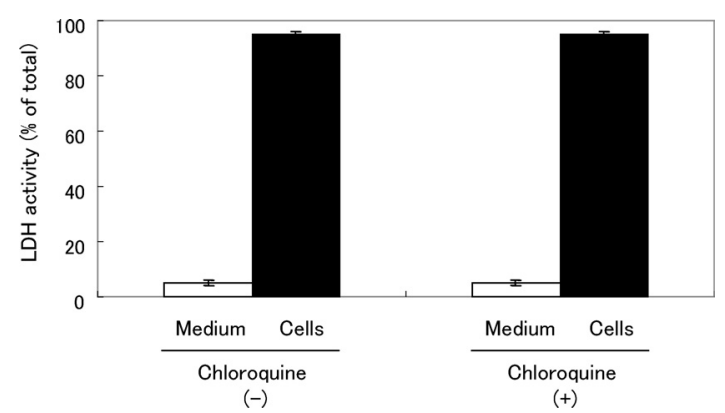

Fig. 7. LDH Activity in the Medium of Rat Hepatocytes

Rat hepatocytes were cultured in the presence or absence of $50 \mu \mathrm{M}$ chloroquine for $3 \mathrm{~h}$. Thereafter, the cells were homogenized with $1.5 \mathrm{ml}$ of isotonic sucrose solution containing $1 \%$ Triton X-100 and centrifuged at $106000 \times \boldsymbol{g}$ for $1 \mathrm{~h}$. LDH activity in the supernatant ( $\square$ ) and medium $(\square)$ was measured and expressed as a percentage of the total. Data are the means of three identical experiments, and the variation of the values was $5 \%$.

cells, LDH activity in the medium of chloroquine-treated or nontreated cells was measured. The proportion of LDH (4\%) in the medium of chloroquine-treated cells was similar to that in the medium of nontreated cells (Fig. 7). These results indicate that almost all chloroquine-treated cells survived and the low level (15\%) of disruption of lysosomes in cells was not due to cell death.

\section{DISCUSSION}

Wattiaux et al. showed that chloroquine shifts the localization of lysosomal marker enzymes such as cathepsin B in a sucrose gradient towards the low density regions when rat hepatocytes are fractionated after rats receive chloroquine injection (in vivo). ${ }^{9)}$ In our experiments, the dense lysosomes were disrupted when hepatocytes were cultured in the presence of chloroquine (in vitro). The different effects of chloroquine on the densest lysosomes of hepatocytes in vivo and in vitro are probably due to the differential efficiency of accumulation of chloroquine in lysosomes. Alternatively, fragility might increase in the dense lysosomes after long periods of culturing of hepatocytes, because cultured cells in vitro receive less nutrients than cells in vivo. According to de Duve et al., the disruption of lysosomes induced by chloroquine results from the accumulation of the drug in these organelles, which induces osmotic swelling. ${ }^{5)}$ Sugioka and Suzuki reported that chloroquine forms a coordination complex with ferriprotoporphyrin IX and this complex strongly promotes the peroxidative cleavage of phospholipid membranes. ${ }^{19)}$ Chloroquine would readily couple with ferriprotoporphyrin IX released from hemoproteins sequestered into lysosomes and cause phospholipid peroxidation and consequently in- crease the membrane fragility. This increase in membrane fragility, in combination with the increased osmotic pressure, would result in lysosomal disruption. In conclusion, our findings indicated that chloroquine is initially caused disruption of lysosomes $(15 \%)$ in the living cells by an increase of lysosomal membrane fragility as well as an increase in osmotic pressure, and secondarily caused disruption of lysosomes $(13 \%)$ during homogenization or centrifugation during cell fractionation.

In the present study, we established an experimental method for monitoring the disruption of lysosomes using a lysosomotropic amine by measuring $\beta-\mathrm{G}$ activity or the amount of lamp-1 in Percoll density gradient fractions, in the cytosolic fraction obtained from cells permeabilized by digitonin or obtained by conventional cell fractionation. Further studies will be necessary to clarify the detailed mechanism of the disruption of lysosomes by chloroquine and the effects of lysosomotropic amines or anti-malarial drugs other than chloroquine on lysosomes.

\section{REFERENCES}

1) Holtzman E., "Lysosomes," Plenum Press, New York, 1989.

2) Kornfeld S., Mellman I., Annu. Rev. Cell. Biol., 5, 483 -525 (1989).

3) Futai M., Oka T., Moriyama Y., Wada Y., J. Biochem. (Tokyo), 124, 259-267 (1998).

4) Dell'Angelica E. C., Mullins C., Caplan S., Bonifacino J. S., FASEB J., 14, 1265-1278 (2001)

5) De Duve C., de Barsy T., Poole B., Trouet A., Tulkens P., Van Hoof F., Biochem. Pharmacol., 23, 2495-2531 (1974).

6) Dean R. T., Jessup W., Roberts C. R., Biochem. J., 217, 27-40 (1984).

7) Mellman I., Fuchs R., Heleninus A., Annu. Rev. Biochem., 55, 663700 (1986).

8) Limet J. N., Ruintart J., Schneider Y. J., Courtoy P. J., Eur. J. Biochem., 146, 539-548 (1985).

9) Wattiaux R., Gentinne F., Jadot M., Dubois F., Wattiaux-De Coninck S., Biochem. Biophys. Res. Commun., 190, 808-813 (1993).

10) Seglen P. O., Methods Cell Biol., 13, 29-83 (1976).

11) Michihara A., Sawamura M., Yamori Y., Akasaki K., Tsuji H., Biol. Pharm. Bull., 24, 1235-1240 (2001).

12) De Duve C., Pressman B. C., Gianetto R., Wattiaux R., Appelmans F., Biochem. J., 60, 604-617 (1955).

13) Robins E., Hirsch H. E., Emmons S. S., J. Biol. Chem., 243, 42464252 (1968).

14) Ikehara Y., Mansho K., Takahashi K., Kato K., J. Biochem. (Tokyo), 83, 1471-1483 (1978).

15) Abei H., "Methods of Enzymatic Analysis," Vol. 2, ed. by Bergmeyer H. U., Verlag Chemie, Wienheim, 1974, pp. 673-684.

16) Lowry O. H., Rosebrough N. J., Farr A. L., Randall R. J., J. Biol. Chem., 193, 265-275 (1951).

17) Laemmli U. K., Nature (London), 227, 680-685 (1970).

18) Towbin H., Staehelin T., Gordon J. Proc. Natl. Acad. Sci. U.S.A., 76, 4350-4354 (1979).

19) Sugioka Y., Suzuki M., Biochem. Biophys. Acta, 1074, 19-24 (1991). 